\title{
Use of Rivaroxaban for the Effective Management of Disseminated Intravascular Coagulation Associated with Abdominal Aortic Aneurysm
}

\author{
Hiroaki Kawano ${ }^{1}$, Tomoko Hata $^{2}$, Akiko Uda ${ }^{3}$ and Koji Maemura ${ }^{1}$
}

\begin{abstract}
A 67-year-old man with non-valvular atrial fibrillation (AF) and previous myocardial and cerebral infarctions had uncontrollable bleeding after undergoing dental extraction because of an exacerbation of chronic disseminated intravascular coagulation (DIC) due to an abdominal aortic aneurysm. After successful treatment of the bleeding with the transfusion of fresh frozen plasma and platelets, nafamostat mesilate was used to treat the chronic DIC. Finally, rivaroxaban (an oral direct Factor Xa inhibitor) was prescribed for chronic DIC, as well as non-valvular AF. Following the initiation of rivaroxaban, the chronic DIC gradually improved, and the patient was discharged.
\end{abstract}

Key words: atrial fibrillation, anticoagulant, disseminated intravascular coagulation

(Intern Med 54: 2625-2628, 2015)

(DOI: 10.2169/internalmedicine.54.4942)

\section{Introduction}

Disseminated intravascular coagulation (DIC) is an acquired bleeding disorder characterized by an imbalance in the hemostatic process, resulting in extensive thrombosis and hemorrhagic complications (1). It occurs in a wide variety of clinical conditions, and aortic dissection and an aortic aneurysm are known to cause DIC (2). A previous report suggested that up to $4 \%$ of aneurysms are complicated by DIC, while 39\% show subclinical elevations of fibrindegradation products (3). Moreover, some trigger events have been reported to induce an acute and decompensated state of DIC (4), and it has been reported in 4 previous cases that either tooth extraction or dental treatment can induce an exacerbation of chronic DIC associated with aortic aneurysms (5-8). Heparin is a conventional therapy for DIC, but it has some restrictions for outpatients because it requires either infusion or subcutaneous injection. Oral agents are convenient for outpatients, but warfarin is usually ineffective for DIC because it does not inhibit activated clotting factors in DIC even though it decreases levels of vitamin Kdependent clotting factors.

Novel oral anticoagulants (NOACs) represent alternatives to warfarin anticoagulation for the prevention of nonhemorrhagic stroke and systemic embolic events in patients with non-valvular atrial fibrillation, especially because NOACs are generally associated with a lower risk of intracranial bleeding than warfarin (9). Moreover, a recent case report showed that the orally administered direct Factor Xa (FXa) inhibitor, rivaroxaban, one of the NOACs, was effective for treating a patient with DIC associated with an aortic aneurysm (10).

In this report, we describe a case of acute exacerbation of chronic DIC associated with an aortic aneurysm with nonvalvular atrial fibrillation after tooth extraction, in which successful management with the orally administered direct FXa inhibitor, rivaroxaban, thus made it possible to successfully carry out treatment on an outpatient basis.

\footnotetext{
${ }^{1}$ Department of Cardiovascular Medicine, Nagasaki University Graduate School of Biomedical Sciences, Japan, ${ }^{2}$ Department of Hematology, Atomic Bomb Disease and Hibakusha Medicine Unit, Atomic Bomb Disease Institute, Nagasaki University, Japan and ${ }^{3}$ Department of Clinical Oral Oncology, Nagasaki University Graduate School of Biomedical Sciences, Japan

Received for publication January 11, 2015; Accepted for publication February 22, 2015

Correspondence to Dr. Hiroaki Kawano, hkawano@nagasaki-u.ac.jp
} 


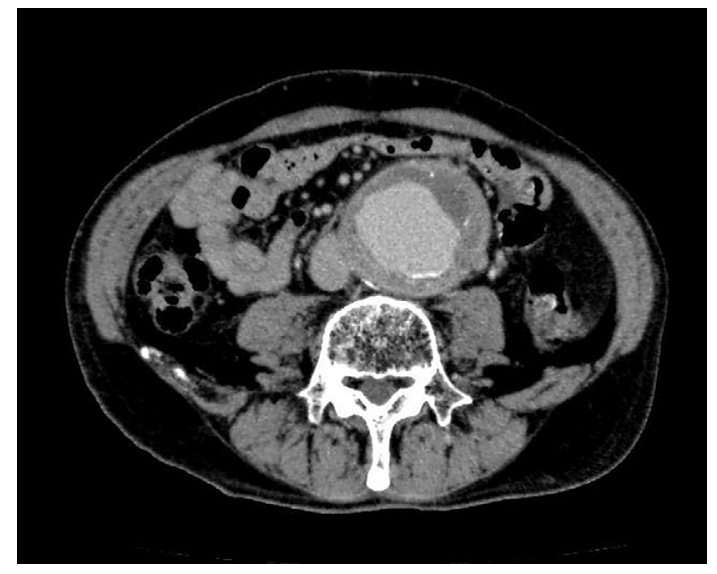

Figure 1. Abdominal aortic aneurysm observed by contrastenhanced chest computed tomography (CT).

\section{Case Report}

A 67-year-old man underwent tooth extraction because he had noticed spontaneous bleeding from the gingiva in association with tooth instability. After the tooth extraction was performed in the Department of Clinical Oral Oncology in our hospital, intermittent hemorrhage continued, and his oral cavity was almost completely filled with a blood clot, even though local hemostatic treatments were performed along with the cessation of aspirin for the secondary prevention of ischemic heart disease. The dentists consulted us four days after the tooth extraction because the man was our outpatient in the Department of Cardiology. He had been diagnosed to have chronic DIC due to an abdominal aortic aneurysm 7 months earlier although he had not had any hemorrhagic events since then. At that time, his laboratory data were as follows: platelet count, $48,000 / \mu \mathrm{L}$; prothrombin time international normalized ratio (PT-INR), 1.15; activated partial thromboplastin time (APTT), $37.2 \mathrm{~s}$ (normal range: 25.2-34.4 s); fibrinogen, $93 \mathrm{mg} / \mathrm{dL}$ (normal range: 168-329 $\mathrm{mg} / \mathrm{dL}$ ); fibrinogen degradation products (FDP), $46.9 \mu \mathrm{g} / \mathrm{mL}$ (normal range: $<5 \mu \mathrm{g} / \mathrm{mL}$ ); D-dimer, $16.0 \mu \mathrm{g} / \mathrm{mL}$ (normal range: $<1 \mu \mathrm{g} / \mathrm{mL}$ ); antithrombin III (ATIII), 87\% (normal range: $75-125 \%$ ); protein $\mathrm{C}, 62 \%$ (normal range: $70-140 \%$ ); protein S, 76\% (normal range: 60-150\%); thrombinantithrombin complex (TAT), $33 \mathrm{ng} / \mathrm{mL}$ (normal range: $<3.0$ $\mathrm{ng} / \mathrm{mL}$ ); $\alpha 2$-plasmin inhibitor, $29 \%$ (normal range: 80 $120 \%$ ); plasmin- $\alpha 2$-plasmin inhibitor complex ( $\alpha 2-\mathrm{PI})$; and $10.6 \mu \mathrm{g} / \mathrm{mL}$ (normal range: $<0.8 \mu \mathrm{g} / \mathrm{mL}$ ). However, he and his family did not agree to surgery because they worried about the complications of the operation given his concomitant illnesses. His past medical history included cerebral hemorrhage due to hypertension at 49 years of age, acute myocardial infarction and coronary bypass surgery at 56 years of age, alveolar hemorrhage with acute pneumonia at 59 years of age, transient ischemic attack at 64 years of age, and hemorrhagic gastric ulcer at 65 years of age. His mother died of cerebral infarction, and his elder sister died of myo- cardial infarction.

His medications included carvedilol (20 mg), enalapril (5 $\mathrm{mg}$ ), furosemide $(40 \mathrm{mg})$, spironolactone $(25 \mathrm{mg})$, nitrate $(20 \mathrm{mg}$ ) for heart failure due to old myocardial infarction, esomeprazole $(20 \mathrm{mg})$ for the prevention of gastric ulcer, and aspirin for the prevention of ischemic heart disease, at a dose of $100 \mathrm{mg}$ every two days because he had ecchymosis. Although he was found to have atrial fibrillation at 58 years of age, he did not agree to take anticoagulant therapy because of his history of severe hemorrhagic events. His $\mathrm{CHA}_{2} \mathrm{DS}_{2} \mathrm{VASc}$ score was $6\left(\mathrm{CHADS}_{2}\right.$ score of 4$)$, and his HAS-BLED score was 4, which indicated a high risk of bleeding.

On admission, his blood pressure was $115 / 75 \mathrm{~mm} \mathrm{Hg}$, his pulse rate was 57/min and irregular, and a Levine grade II systolic murmur was heard at the apex. Subcutaneous hemorrhage was seen on both arms. Electrocardiography showed atrial fibrillation. A chest X-ray showed cardiomegaly with a cardiothoracic ratio of $60 \%$. Echocardiography demonstrated mild left ventricular hypertrophy and diffuse hypokinesis, with a left ventricular ejection fraction of $55 \%$. Contrastenhanced abdominal computed tomography (CT) demonstrated an abdominal aortic aneurysm from the ostium of the superior mesenteric artery to the bifurcation of the common iliac artery (maximal diameter, $62 \mathrm{~mm}$ ) (Fig. 1). His laboratory data were as follows: white blood cell count, $5,100 \times$ $10^{3} / \mu \mathrm{L}$; red blood cell count, $3.59 \times 10^{6} / \mu \mathrm{L}$; hemoglobin, 11.3 $\mathrm{g} / \mathrm{dL}$; hematocrit, 32.4\%; C-reactive protein, $0.08 \mathrm{mg} / \mathrm{dL}$; blood urea nitrogen, $41 \mathrm{mg} / \mathrm{dL}$; creatinine, $1.65 \mathrm{mg} / \mathrm{dL}$; Na, $135 \mathrm{mEq} / \mathrm{L} ; \mathrm{K}, 5.1 \mathrm{mEq} / \mathrm{L} ; \mathrm{Cl}, 102 \mathrm{mEq} / \mathrm{L}$; uric acid, 9.2 $\mathrm{mg} / \mathrm{dL}$; total protein, $7.9 \mathrm{~g} / \mathrm{dL}$; total bilirubin, $1.0 \mathrm{mg} / \mathrm{dL}$; aspartate aminotransferase, $23 \mathrm{IU} / \mathrm{L}$; alanine aminotransferase, $15 \mathrm{IU} / \mathrm{L}$; lactate dehydrogenase, $212 \mathrm{IU} / \mathrm{L}$; creatine kinase, $56 \mathrm{IU} / \mathrm{L}$; total cholesterol, $148 \mathrm{mg} / \mathrm{dL}$; fasting plasma glucose, $105 \mathrm{mg} / \mathrm{dL}$; hemoglobin A1c, 5.6\%; N terminal-pro brain natriuretic peptide, $901.7 \mathrm{pg} / \mathrm{mL}$; and platelet count, $60,000 / \mu \mathrm{L}$. His PT-INR was 1.21 , APTT was $42.5 \mathrm{~s}$, fibrinogen was $141 \mathrm{mg} / \mathrm{dL}$, FDP was $40.4 \mu \mathrm{g} / \mathrm{mL}$, and D-dimer was $12.2 \mu \mathrm{g} / \mathrm{mL}$.

He was treated with a platelet transfusion (10 units), fresh frozen plasma (FFP) infusion $(480 \mathrm{~mL})$, and nafamostat mesilate $(50 \mathrm{mg} /$ day intravenous infusion for two days), and the bleeding stopped. Three days later, intravenous infusion of nafamostat mesilate at $50 \mathrm{mg} /$ day was started because recurrence of bleeding from the tooth socket occurred, and the rebleeding ceased. However, nafamostat mesilate had to be stopped after its administration for five days because of hyperkalemia $(6.1 \mathrm{mEq} / \mathrm{L})$ as an adverse effect. Then, because he had non-valvular atrial fibrillation, rivaroxaban, a direct FXa inhibitor indicated for the prevention of thromboembolism due to atrial fibrillation, was used in an attempt to improve the chronic DIC and prevent rebleeding. Rivaroxaban was started at a dose of $10 \mathrm{mg}$ once daily because the patient's weight was $62.4 \mathrm{~kg}$, his serum creatinine level was $1.65 \mathrm{mg} / \mathrm{dL}$, and creatinine clearance was $38 \mathrm{~mL} / \mathrm{min}$. After starting rivaroxaban, the chronic DIC improved gradually 


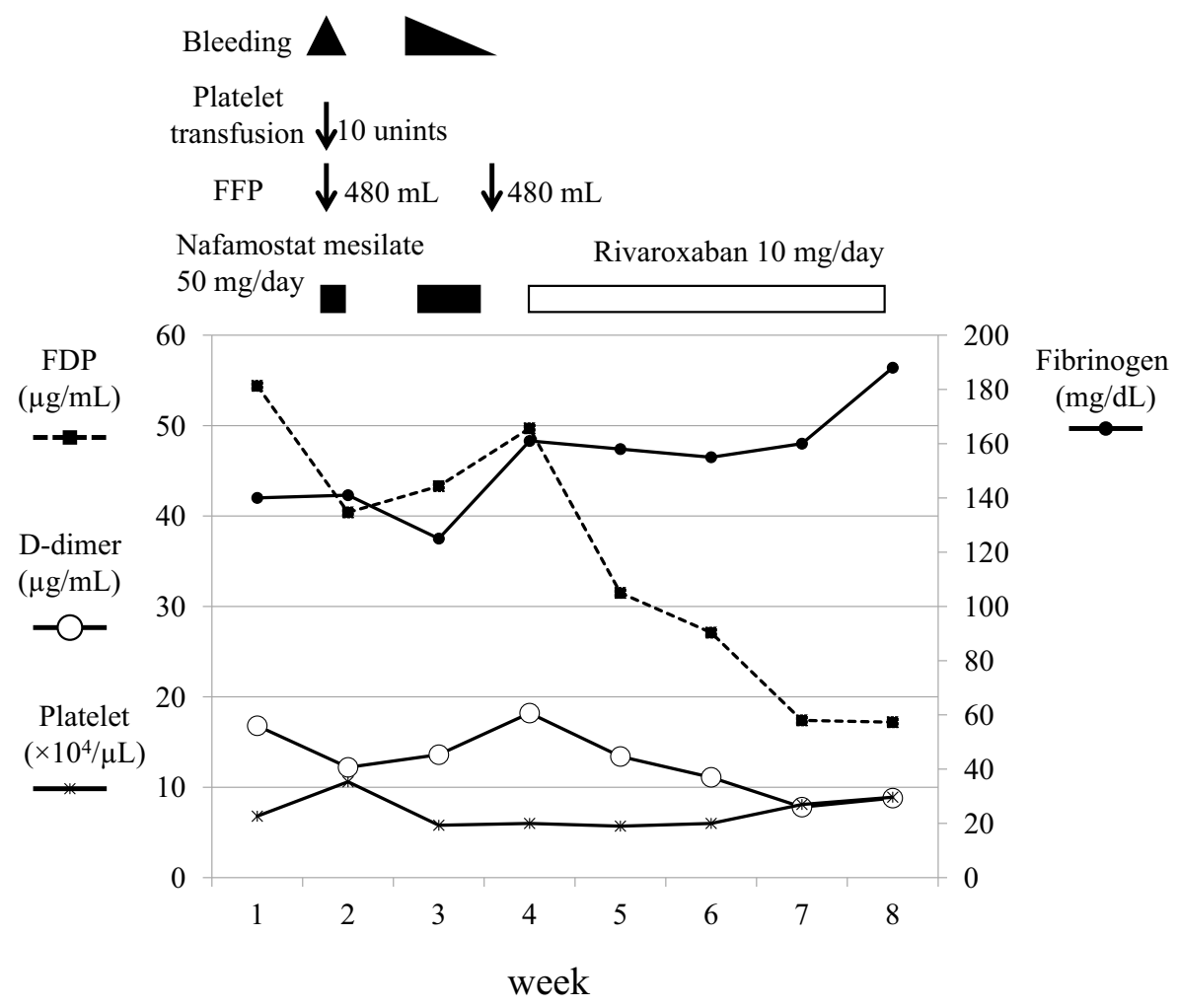

Figure 2. Clinical course of anticoagulant therapy and changes in the platelet count, fibrinogen, fibrinogen degradation products, and D-dimer. FDP: fibrinogen degradation products

(Fig. 2), and he was discharged, after which, his condition remained stable for 6 months. ATIII was around $80 \%$ during admission and after discharge. Although TAT and $\alpha 2$-PI levels were not measured during admission, TAT was around $10 \mathrm{ng} / \mathrm{mL}$, and $\alpha 2$-PI was around $60 \%$ from 1 to 6 months after discharge. These values improved compared to the previous levels at the time of diagnosis of chronic DIC without rivaroxaban (TAT, $33 \mathrm{ng} / \mathrm{mL}$; $\alpha 2-\mathrm{PI}, 29 \%$ ).

\section{Discussion}

Surgical correction is the treatment of choice in patients with DIC associated with aortic aneurysm, but for inoperable patients, medical therapy can be used to control the coagulopathy. Previous studies have demonstrated that the effective adjunctive treatments for chronic DIC due to aortic aneurysm were: continuous heparin infusion (11), subcutaneous injection of low molecular weight heparin $(6,12-14)$, the intravenous injection of danaparoid with the oral administration of tranexamic acid (15), and thrombomodulin $(16,17)$ with or without platelet and FFP transfusion for the acute phase of exacerbation of chronic DIC. However, the intravenous or subcutaneous administration of these medicines for the prevention of an exacerbation of chronic DIC in outpatients for an extended period of time is difficult. Although camostat mesilate, an oral agent, in addition to aspirin and warfarin, has been reported to be an effective treatment for asymptomatic DIC due to aortic aneurysm $(18,19)$, the drug was found to be ineffective for re- lapsed DIC (14). The present patient had a risk of airway obstruction from the blood clot in his oral cavity. Moreover, PT and APTT on admission were more prolonged than had been previously observed (these parameters and fibrinogen were not measured just after bleeding), and the effect of aspirin seemed to be sustained. Therefore, platelet transfusion and FFP infusion were performed to stop the bleeding. Nafamostat mesilate was selected instead of heparin because his oral bleeding was severe. Although his bleeding was almost controlled by nafamostat mesilate, it was necessary to stop the drug because of hyperkalemia. Rivaroxaban, one of the direct FXa inhibitors, was then selected instead of heparin because the patient had atrial fibrillation and a high risk of bleeding and because it could be given orally on an outpatient basis, unlike heparin, which requires injection.

Although in Japan today the main indication for NOACs, including rivaroxaban, is for the prevention of thromboembolism in non-valvular atrial fibrillation, there have been three previous reports of the use of rivaroxaban for the treatment of DIC; in one case, associated with Klippel-Trénaunay syndrome (20), associated with aortic aneurysm in another case (10), and associated with severe infection in the final case (21). Thus, at the present time, rivaroxaban seems to be one of the best medicines for outpatients with DIC associated with aortic aneurysm and non-valvular atrial fibrillation. In aortic aneurysms, endothelial disruption associated with either dissection or atheromatous plaque rupture causes the exposure of collagen and tissue factor. This triggers the coagulation cascade, including the activation of FX, leading 
to consumption of clotting factors in excess of the synthetic capacity, and thus inducing DIC. Because rivaroxaban inhibits FXa, it may suppress DIC progression associated aortic aneurysms. However, the precise mechanism of action of rivaroxaban in patients with DIC associated with aortic aneurysm is unknown. Moreover, there have been no reports of the effects of other NOACs. Further study is therefore needed to elucidate the effectiveness and indications of NOACs, including rivaroxaban, for DIC associated with aortic aneurysm.

In conclusion, rivaroxaban may be useful for chronic DIC in association with aortic aneurysm in outpatients.

The authors state that they have no Conflict of Interest (COI).

\section{Acknowledgement}

The authors would like to thank Dr. T. Ohmori (Research Division of Cell and Molecular Medicine, Center for Molecular Medicine, Jichi Medical School of Medicine) for his valuable advice.

\section{References}

1. Levi M, Cate HT. Disseminated intravascular coagulation. N Engl J Med 341: 586-592, 1999.

2. Aboulafia DM, Aboulafia ED. Aortic aneurysm-induced disseminated intravascular coagulation. Ann Vasc Surg 10: 396-405, 1996.

3. Fisher D, Yawn D, Crewfold S. Preoperative disseminated intravascular coagulation associated with aortic aneurysms. Arch Surg 118: 1252-1255, 1983.

4. Kamel K, Hoerman KC. Disseminated intravascular coagulation. J Oral Surg 31: 95-97, 1973.

5. Chishiro T. A case of disseminated intravascular coagulation thought to be caused by tooth extraction in the hypercoagulable condition due to abdominal aortic aneurysm. Nihon Naika Gakkai Zasshi (J Jpn Soc Int Med) 78: 1777-1778, 1989 (in Japanese).

6. Peters KA, Triolo PT, Darden DL. Disseminated intravascular coagulopathy: manifestations after a routine dental extraction. Oral Surg Oral Med Oral Pathol Oral Radiol Endod 99: 419-423, 2005.

7. Herold J, Falworth MA. Disseminated intravascular coagulopathy presenting as a bleeding tooth socket. Br Dent J 177: 21-22, 1994.

8. Kunitake Y, Doi K, Sakai H, Nakabayashi M, Oki M, Ryoke K. A case of hemorrhagic after tooth extraction caused by DIC due to an aneurysm. Nihon Koku Geka Gakkai Zasshi (Jpn J Oral Maxillofac Surg) 53: 40-44, 2007 (in Japanese).

9. Miller CS, Grandi SM, Shimony A, Filion KB, Eisenberg MJ. Meta-analysis of efficacy and safety of new oral anticoagulants (dabigatran, rivaroxaban, apixaban) versus warfarin in patients with atrial fibrillation. Am J Cardiol 110: 453-460, 2012.

10. Hayashi T, Nakagawa N, Kadohira Y, Morishita E, Asakura H. Ri- varoxaban in a patient with disseminated intravascular coagulation associated with an aortic aneurysm: a case report. Ann Intern Med 161: 158-159, 2014.

11. Jelenska MM, Szmidt $J$, Bojakowski K, Grzela $T$, Palester-Chlebowczyk M. Compensated activation of coagulation in patients with abdominal aortic aneurysm: effects of heparin treatment prior to elective surgery. Thromb Haemost 92: 9971002, 2004.

12. Cummins D, Segal H, Hunt BJ, Awad R, Maddox A. Chronic disseminated intravascular coagulation after surgery for abdominal aortic aneurysm: clinical and haemostatic response to dalteparin. Br J Haematol 113: 658-660, 2001.

13. Majumdar G. Long-term management of chronic DIC associated with inoperable aortic aneurysm with low molecular weight heparin. Hematol J 5: 447-448, 2004.

14. Miyahara S, Yasu T, Yamada Y, Kobayashi N, Saito M, Momomura S. Subcutaneous injection of heparin calcium controls chronic disseminated intravascular coagulation associated with inoperable dissecting aortic aneurysm in an outpatient clinic. Intern Med 46: 727-732, 2007.

15. Ontachi Y, Asakura H, Arahata M, et al. Effect of combined therapy of danaparoid sodium and tranexamic acid on chronic disseminated intravascular coagulation associated with abdominal aortic aneurysm. Circ J 69: 1150-1153, 2005.

16. Iyama $S$, Sato $T$, Murase $K$, et al. Intermittent administration of recombinant human soluble thrombomodulin successfully controlled chronic disseminated intravascular coagulation in a patient with dissecting aortic aneurysm on an outpatient basis. Blood Coagul Fibrinolysis 23: 548-550, 2012.

17. Nakamura K, Kawahito K, Naganuma H, et al. A case of disseminated intravascular coagulation complicating thoracic aortic aneurysm for which recombinant human soluble thrombomodulin was effective. Nihon Shinzō Kekkan Geka Gakkai Zasshi (Jpn J Cardiovasc Surg) 41: 148-151, 2012 (in Japanese, Abstract in English).

18. Yoneda K, Amano I, Tanaka H, et al. Effective use of camostat mesilate for chronic disseminated intravascular coagulation complicated by thoracoabdominal aortic aneurysm. Rinsho Ketsueki (Jpn J Clin Hematol) 42: 30-34, 2001 (in Japanese, Abstract in English).

19. Fukuda N, Shimohakamada Y, Nakamori Y, et al. Thoracic aortic aneurysm with chronic disseminated intravascular coagulation treated successfully with orally administered camostat mesilate, warfarin and aspirin. Rinsho Ketsueki (Jpn J Clin Hematol) 43: 199-203, 2002 (in Japanese, Abstract in English).

20. Randrianarisoa E, Kopp HG, Balletshofer BM, et al. Management of disseminated intravascular coagulopathy with direct factor $\mathrm{Xa}$ inhibitor rivaroxaban in Klippel-Trénaunay syndrome. Blood Coagul Fibrinolysis 24: 766-770, 2013.

21. Wagenhäuser MU, Ertas N, Sagban TA, et al. A 61-year-old man with disseminated intravascular coagulation: a case report. Ann Vasc Surg 28: 1566.e17-1566.e22, 2014.

(C) 2015 The Japanese Society of Internal Medicine http://www.naika.or.jp/imonline/index.html 